Provided for non-commercial research and education use. Not for reproduction, distribution or commercial use.

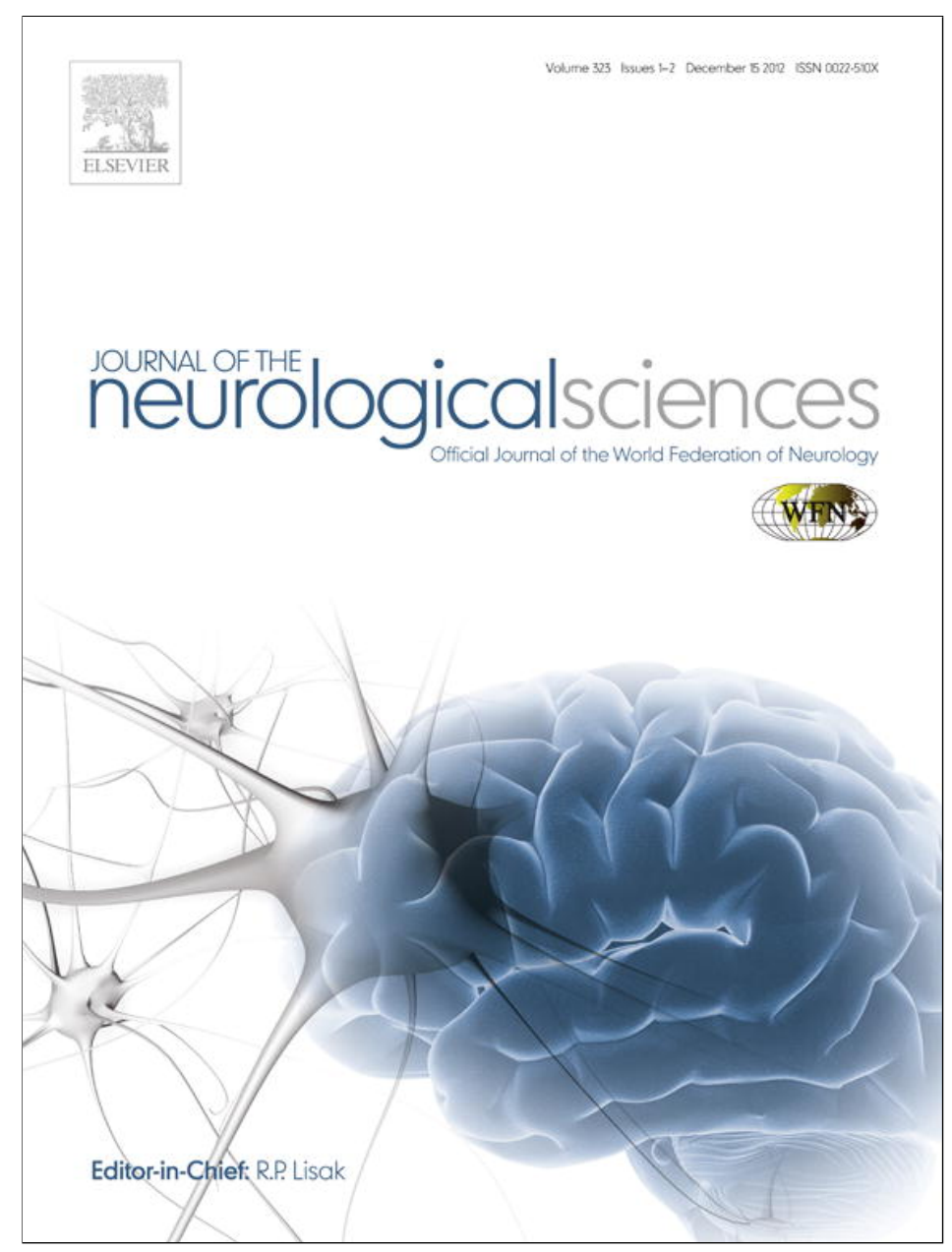

This article appeared in a journal published by Elsevier. The attached copy is furnished to the author for internal non-commercial research and education use, including for instruction at the authors institution and sharing with colleagues.

Other uses, including reproduction and distribution, or selling or licensing copies, or posting to personal, institutional or third party websites are prohibited.

In most cases authors are permitted to post their version of the article (e.g. in Word or Tex form) to their personal website or institutional repository. Authors requiring further information regarding Elsevier's archiving and manuscript policies are encouraged to visit:

http://www.elsevier.com/copyright 


\title{
Tracheostomy mechanical ventilation in patients with amyotrophic lateral sclerosis: Clinical features and survival analysis
}

\author{
Rossella Spataro a, Valeria Bono ${ }^{\text {a }}$, Santino Marchese ${ }^{\mathrm{b}}$, Vincenzo La Bella ${ }^{\mathrm{a}, *}$ \\ a ALS Clinical Research Center, Bio.Ne.C, University of Palermo, 90129 Palermo, Italy \\ ${ }^{\mathrm{b}}$ Respiratory Intensive Care Unit, ARNAS Civico General Hospital, 90127 Palermo, Italy
}

\section{A R T I C L E I N F O}

\section{Article history:}

Received 23 December 2011

Received in revised form 5 August 2012

Accepted 9 August 2012

Available online 16 September 2012

\section{Keywords:}

Tracheostomy

Amyotrophic lateral sclerosis

Clinical features

Survival

\begin{abstract}
A B S T R A C T
Background: Tracheostomy mechanical ventilation (TMV) is performed in amyotrophic lateral sclerosis (ALS) patients with a respiratory failure or when the non-invasive ventilation (NIV) is no longer effective. We evaluated the clinical characteristics and survival of a cohort of tracheostomized ALS patients, followed in a single ALS Clinical Center.

Methods: Between 2001 and 2010, 87 out of 279 ALS patients were submitted to TMV. Onset was spinal in 62 and bulbar in 25. After tracheostomy, most patients were followed up through telephone interviews to caregivers. A complete survival analysis could be performed in fifty-two TMV patients.

Results: $31.3 \%$ ALS patients underwent tracheostomy, with a male prevalence $(\mathrm{M} / \mathrm{F}=1.69)$ and a median age of 61 years (interquartile range $=47-66$ ). After tracheostomy, nearly all patients were under home care. TMV ALS patients were more likely than non-tracheostomized (NT) patients to be implanted with a PEG device, although the bulbar-/spinal-onset ratio did not differ between the two groups. Kaplan-Meyer analysis showed that tracheostomy increases median survival (TMV, 47 months vs NT, 31 months, $\mathrm{p}=0.008$ ), with the greatest effect in patients younger than 60 at onset (TMV $\leq 60$ years, 57.5 months vs NT $\leq 60$ years, 38.5 months, $\mathrm{p}=0.002$ ).

Conclusions: TMV is increasingly performed in ALS patients. Nearly all TMV patients live at home and most of them are fed through a PEG device. Survival after tracheostomy is generally increased, with the stronger effect in patients younger than 60. This survival advantage is apparently lost when TMV is performed in patients older than 60 . The results of this study might be useful for the decision-making process of patients and their families about this advanced palliative care.
\end{abstract}

(C) 2012 Published by Elsevier B.V.

\section{Introduction}

Amyotrophic lateral sclerosis (ALS) is a neurodegenerative disorder leading to a progressive motor neuron loss of function and death, with the affected patients showing a wide spectrum of signs and symptoms, such as limb paresis and muscle atrophy, dysphagia, dysarthria, and loss of respiratory function [1].

Although in the last years the intensive management of ALS has improved the patients' quality of life and survival [2-6], in most cases the natural course of the disease still ends within 3-5 years from the onset $[7,8]$. The leading cause of death is respiratory failure [8].

When respiratory failure becomes too severe to be managed by non invasive ventilation (NIV) and/or when airway mucus accumulation can no longer be cleared with common methods (e.g., symptomatic drugs, respiratory physical therapy, cough-assist machine), a

* Corresponding author at: ALS Clinical Research Center, Bio.Ne.C, Via G La Loggia 1, 90129 Palermo, Italy. Tel./fax: + 390916555158.

E-mail address: vincenzo.labella@unipa.it (V. La Bella). tracheostomy and subsequent invasive mechanical ventilation (TMV) can be performed $[9,10]$.

It has been suggested that TMV can prolong survival for patients with advanced ALS [10-13]. However, the median survival after tracheostomy differs among studies, ranging from about 8 months up to about 3 years [11-13]. Several factors have been suggested to affect survival in TMV ALS patients: age at onset (younger patients may survive longer), the severity of motor disability (higher scores at ALSFRS are predictive of longer survival), or cultural variables [12-14].

After tracheostomy, most European and American ALS patients are discharged home or to long-term care facilities, whereas more than a half of Japanese patients live in hospital [11-13,15,16].

Only a minority of ALS patients from western countries (up to $10.6 \%$ in a single study [12]) are reported to undergo tracheostomy $[12,17,18]$. This figure rises to up to $30 \%$ in a recent Japanese study, suggesting a cross-cultural difference for the advanced management of these patients [11]. Furthermore, a few studies suggest that tracheostomy may have a good acceptance rate, even when performed without being discussed in advance $[13,15]$. There is, however, no 
sufficient information on the disease progression in tracheostomized patients. The Appel ALS rating scale (AARS) and the widely-used revised version of the ALS functional rating scale (ALSFRS-R) tend to flatten in the advanced stages of the disease [19,20].

This work was undertaken to assess the demographic and clinical characteristics of a cohort of ALS patients followed-up at a single tertiary center who underwent TMV over a 10 -year period. We evaluated the variables that may affect the risk of tracheostomy and the survival rate.

\section{Patients and methods}

The study protocol was approved by the internal Ethics Committee of the Department of Experimental Biomedicine and Clinical Neurosciences, University of Palermo, Italy.

\subsection{Patients}

Between 2001 and 2010, 279 sporadic $(n=265)$ and familial $(n=$ 14) ALS patients $(M / F=1.29)$ were prospectively followed-up until death or tracheostomy in a single tertiary ALS referral Center in Palermo, Italy. All patients met the diagnostic criteria for possible, probable or definite ALS, according to the EL Escorial/WFN revised criteria [21]. Patients with a clinical diagnosis of suspected ALS, Primary Lateral Sclerosis and Progressive Muscular Atrophy were excluded from this study. ALS patients (either sporadic or familial) with frontotemporal dementia were also excluded. Ninety-two percent of our entire ALS cohort took regularly riluzole $(100 \mathrm{mg} /$ day) until death or tracheostomy.

192 patients $(\mathrm{M} / \mathrm{F}=1.16)$ died without being submitted to TMV. The main cause of death was respiratory failure (data on the causes of death of a large fraction of these patients have been recently published) [8]. 87 patients $(\mathrm{M} / \mathrm{F}=1.69)$ underwent $\mathrm{TMV}$, and in $40.3 \%$ it was the result of an advance directive. Tracheostomies were performed as surgical procedure in an ICU.

After tracheostomy, most patients were followed up through periodic telephone contacts [22]. In a minority of cases (11.6\%) we performed home visits. After tracheostomy, the percentage of patients still taking riluzole dropped to $74.7 \%$. Respiratory and general management was provided to the TMV patients by periodic re-admissions in the respiratory ICU or at their home through the home care plan of the Italian Health Care System.

\subsection{Methods}

Demographic and clinical information, laboratory, neurophysiological and imaging data were recorded for all patients in the two groups (i.e. patients who underwent TMV or not). To this purpose we used an electronic database (Access Microsoft ${ }^{\circledR}$ Corp., Redmond, WA, USA).

Patients were submitted to follow-up visits by our multi- and trans-disciplinary team in the ALS Clinic every 3-4 months to monitor the clinical progression, the respiratory and swallowing functions and the cognitive and psychological status. Seated erect Forced Vital Capacity (FVC), nocturnal oxymetry and blood gas analysis were used as indexes of respiratory function, whereas the severity of dysphagia was evaluated through the one-hundred milliliter water swallow test [3]. When necessary, a PEG device was placed and/or a NIV was initiated $[3,23]$, according to standard management procedures [24]. Disease progression was evaluated through two clinimetric rating scales: i) the Appel ALS Rating Scale (AARS) and ii) the revised ALS functional rating scale (ALSFRS-R) $[19,20]$. Based on a gain of $n$ points per month ( $\triangle A A R S)$, AARS allows identification of at least three different rates of progression, i.e. slow (gain: 0-2 points/ month), intermediate (gain: 2-4 points/month) and rapid (gain: $>4$ points/month) [19]. Disease progression was also measured through an ALSFRS-R rate calculated as: $\triangle F S=$ (ALSFRS-R at onset - ALSFRS- $R$ at time of diagnosis)/diagnostic delay (months) [25]. According to the $\Delta \mathrm{FS}$, three rates of progression could be calculated, i.e. slow $(\Delta \mathrm{FS}<0.5)$, intermediate $(\Delta \mathrm{FS} 0.5-1)$, and rapid $(\Delta \mathrm{FS} \geq 1)[25]$.

\subsubsection{Data analysis and statistics}

All analyses were made using SIGMASTAT and SPSS 17 software packages. Variables were expressed as median with interquartile ranges (IQR). Non parametric data comparisons were performed using Mann-Whitney rank sum test. Correlations were studied with the Spearman's test. Differences between groups were evaluated using the chi-square test or, where appropriate, the Fisher exact test. Survival data were expressed as median with IQR and analyses were performed with the Kaplan-Meier method. Survival curves were compared with the log-rank test. The Cox regression model was utilized to verify whether age at onset was an independent predictor of survival in tracheostomized patients vs not tracheostomized. Multivariate logistic regression analysis was performed to assess which variables are likely to be associated with a risk of tracheostomy. Independent variables were: FVC at diagnosis and at the time of

Table 1

Clinical and demographic characteristics of the deceased (not tracheostomized) and the tracheostomized (deceased and not) ALS patients followed over a 10-year period (2001-2010) in a single ALS Clinical Tertiary Center.

\begin{tabular}{|c|c|c|}
\hline Variable & Patients not tracheostomized $(\mathrm{n}=192)$ & Patients tracheostomized $(n=87)$ \\
\hline \multicolumn{3}{|l|}{ Age at onset (years) } \\
\hline Median (range) & $63(55-71)$ & $61(47-66)$ \\
\hline $\mathrm{M} / \mathrm{F}$ & 1.16 & 1.69 \\
\hline \multicolumn{3}{|l|}{ Site of onset } \\
\hline Spinal (n, \%) & $131(68.2)$ & $62(71.2)$ \\
\hline Bulbar (n. \%) & $61(31.8)$ & $25(28.8)$ \\
\hline \multicolumn{3}{|c|}{ Disease duration until death or tracheostomy (months) } \\
\hline Median (range) & $31(20-47)$ & $35(23-48)$ \\
\hline Riluzole therapy (n, \%) & $175(91)$ & $65(74.7)^{*}$ \\
\hline Patients with PEG (n, \%) & $62(32.3)$ & $57(65.5)^{* *}$ \\
\hline \multicolumn{3}{|c|}{ Patients with NIV ( $\geq 4 \mathrm{~h} /$ day) before death or tracheostomy } \\
\hline$(\mathrm{n}, \%)$ & $85(44.3)$ & $37(42.5)$ \\
\hline \multicolumn{3}{|c|}{ Living conditions after tracheostomy } \\
\hline Under home care (\%) & NA & 94.3 \\
\hline In hospital (\%) & NA & 5.7 \\
\hline
\end{tabular}

Tracheostomized vs not tracheostomized.

${ }^{*} \mathrm{p}<0.001$ (Chi-square).

** $\mathrm{p}=0.0016$, (Fisher's exact test). 
death/tracheostomy, rate of respiratory decline, as measured by change of $\mathrm{FVC}$ /disease duration (months), $\triangle \mathrm{FS}$, age at onset, diagnostic delay (months) and survival. For all analyses, $p$-values $<0.05$ were considered significant.

\section{Results}

\subsection{Clinical and demographic characteristics of the TMV ALS patients}

From 2001 through 2010, 279 ALS patients were followed at our tertiary ALS Center until death or tracheostomy. Patients undergoing tracheostomy $(n=87,31.3 \%)$ were further followed up with regular telephone contacts (100\%) and/or home visits (11.6\%). The demographic and clinical characteristics of the deceased non-tracheotomized (NT) ALS patients and those (both deceased and not) who underwent tracheostomy (TMV) are summarized in Table 1.

There was a male prevalence in the TMV patients (M/F: TMV, 1.69 vs NT, $1.16, \mathrm{p}=\mathrm{ns}$ ), with no significant difference in the age at onset between the two groups. Furthermore, the proportion of spinal-onset and bulbar-onset patients was comparable, the bulbar-onset patients accounting for by some $30 \%$ in both groups. Although $92 \%$ of our entire ALS cohort was regularly taking riluzole, this percentage dropped to $74.7 \%$ after tracheostomy ( $p<0.001$ TMV vs NT, chi-square). Several patients in fact autonomously stopped taking the drug after tracheostomy.

TMV ALS patients were more likely to undergo to enteral feeding than the NT patients. As shown in Table 1, two-third $(n=57,65.5 \%)$ of the TMV ALS patients were fed by PEG as compared to 62 patients $(32.3 \%)$ in the NT group ( $p=0.001$, Fisher's exact test). Note that bulbar-onset patients, which invariably show early dysphagia and difficulty to clear airway mucus, are not overrepresented in the TMV group. Based on the swallowing test and, in some patients, the latest BMI, there were in fact not more dysphagic patients among those undergoing TMV (data not shown). We therefore suggest that a PEG device is more likely to be implanted in patients undergoing tracheostomy, irrespective of the severity of the actual dysphagia.

After tracheostomy, over $92 \%$ of patients were on continuous ventilation (i.e., more than $18 \mathrm{~h}$ per day) and $94.3 \%(\mathrm{n}=82)$ lived under home care.

We then assessed which variable is likely to be associated with the risk of tracheostomy in our ALS cohort. As shown in Table 2, a multivariate logistic analysis suggested that both the rate of FVC decline and the disease progression, as measured by $\Delta \mathrm{FS}$, correlate positively with the risk of tracheostomy.

\subsection{The disease progression and the tracheostomy}

ALS is a heterogeneous disorder, with different rates of clinical progression. Patients may worsen rapidly or, conversely, the disease can progress very slowly with a year-long natural history. Among the commonly used clinimetric rating scales, AARS reliably allows identification of three different rates of progression in ALS (i.e., slow, intermediate, rapid) [19]. Two-thirds of the tracheostomized patients (59.8\%)

\section{Table 2}

Multivariate analysis of tracheostomy risk in the ALS cohort.

\begin{tabular}{|c|c|c|c|}
\hline Variable & Odds ratio & $95 \% \mathrm{CI}$ & $\mathrm{p}$ \\
\hline Age at onset & 0.99 & $0.96-1.02$ & 0.43 \\
\hline Diagnostic delay & 0.98 & $0.95-1.02$ & 0.45 \\
\hline FVC at diagnosis & 1.01 & $0.99-1.03$ & 0.09 \\
\hline Last FVC ${ }^{\mathrm{a}}$ & 1.08 & $0.96-1.19$ & 0.035 \\
\hline Rate of FVC decline & 1.28 & $0.99-1.40$ & 0.05 \\
\hline Survival $^{\mathrm{b}}$ & 1.01 & $0.98-1.03$ & 0.39 \\
\hline$\Delta \mathrm{FS}$ & 1.37 & $0.97-1.95$ & 0.07 \\
\hline
\end{tabular}

a Before death or tracheostomy.

b Until death or tracheostomy. showed an intermediate rate of progression, as compared to $41.2 \%$ of NT. Slowly progressing patients were less likely to undergo tracheostomy (only $12.6 \%$ were submitted to this palliative care), whereas rapidly evolving patients were more equally distributed among the two groups (TMV, 27.6\% vs NT, 33.8\%). The difference among groups was found to be significant ( $\mathrm{p}=0.009$, chi-square analysis).

When the disease progression was calculated with $\triangle \mathrm{FS}$, we observed a trend similar to that seen with $\triangle$ AARS. In particular, $20.7 \%$ of the TMV patients showed a slow disease progression, as compared with $30.4 \%$ of the NT; rapidly evolving patients were slightly overrepresented in the TMV group (i.e., $44.8 \%$ TMV vs $38.1 \%$ NT), while patients with an intermediate rate of progression were equally distributed among the two groups (TMV, $34.5 \%$ vs NT, $31.5 \%$ ). The difference between groups however did not reach significance (chi-square $=2.95$, DF 2, p = 0.229). Although a low concordance between AARS and ALSFRS-R with disease progression has been suggested [26], we found a significant correlation between the two rating scales, both in TMV and NT patients (TMV, $\mathrm{r}=0.41, \mathrm{p}=$ 0.045; NT, $r=0.27, p=0.005$, Spearman Rank Order Correlation).

In conclusion, both $\triangle \mathrm{AARS}$ and $\triangle \mathrm{FS}$ suggest that slowly progressing patients might be at a relatively lower risk for tracheostomy.

\subsection{Survival}

Among the TMV ALS patients, thirty-five were still alive at the time of this study whereas the remaining fifty-two patients ( $\mathrm{M} / \mathrm{F}=$ 1.73) were followed-up for their extended natural history, i.e. from onset/diagnosis through tracheostomy until death. The age at onset of this latter group was 62 years (IQR $=53-67)$, with a median disease duration from onset to tracheostomy of 35 months (IQR $=$ 23-48).

Fig. 1 shows the survival plot of the deceased TMV and the NT ALS patients. As expected, the TMV prolonged survival, thus bringing patients well beyond their natural history of disease. The median survival from onset to death was 47 months (IQR $=33-61)$ for TMV and 31 months (IQR $=20-47)$ for non-tracheostomized patients $(\mathrm{p}=$ 0.008 , log-rank test).

Thirteen TMV patients $(25 \%, \mathrm{M} / \mathrm{F}=1.6)$ died within the first month following tracheostomy. Of these, $84 \%$ underwent tracheostomy as an emergency procedure, twelve had had a spinal onset and in one patient onset was bulbar; the median age at disease onset was 64 years $(\mathrm{IQR}=61-71)$. These patients showed FVC values, at the time of the surgical procedure, significantly lower than the group who survived longer (Table 3). Furthermore, by analyzing the whole group of deceased TMV patients, we found that a low FVC before

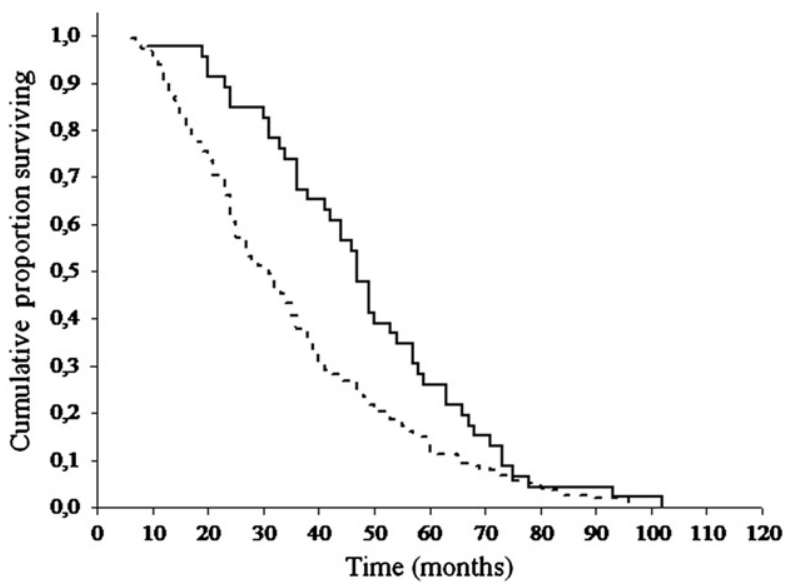

Fig. 1. Kaplan-Meyer survival curve of the ALS patients who underwent tracheostomy (continuous line; median survival [months] 47 [IQR=33-61]) and ALS patients that died without being submitted to tracheostomy (broken line; median survival [months] $31[\mathrm{IQR}=20-47]) . \mathrm{p}=0.008, \log$-rank test. 
Table 3

FVC variables related with a poor survival ( $\leq 1$ month) in TMV ALS patients.

\begin{tabular}{lccc}
\hline FVC variable $^{\mathrm{a}}$ & \multirow{2}{*}{$\mathrm{p}$} \\
\cline { 2 - 3 } & $\leq 1(\mathrm{n}=13)$ & $>1(\mathrm{n}=41)$ & \\
\hline Liters, mean (SD) & $0.67(0.44)$ & $1.34(0.60)$ & $0.001^{\mathrm{b}}$ \\
\% predicted, median (range) & $20(18.5-26.5)$ & $32(22.5-39)$ & $0.013^{\mathrm{c}}$ \\
\hline a & & \\
b Sast FVC values taken before tracheostomy. & & \\
c Student's $t$ test. & & \\
\end{tabular}

tracheostomy correlated positively with a shorter survival $(n=52$, $r=0.44, p=0.02$, Spearman rank order analysis). Several factors, besides the respiratory muscles weakness, are associated with a low FVC in ALS patients, e.g., mouth muscles weakness, airway mucus accumulation, etc. Although we could not ascertain all specific causes leading to death in this group, it is likely that these patients were in a poor clinical status. None among the TMV ALS patients died because of a voluntary decision to come off the ventilation. On the other hand, the Italian law firmly prohibits a patient to voluntarily stop a cure/ treatment, if this is leading to death.

Nineteen patients $(36.5 \%, \mathrm{M} / \mathrm{F}=3.75)$ showed a survival after tracheostomy longer than one year. $52.6 \%$ of patients in this group were primarily bulbar, while the median age at disease onset was 54 years (IQR $=51-63)$.

We also analyzed the median survival of TMV ALS patients by using 60 years as a cut-off age at onset. The Kaplan-Meyer analysis shows that young patients were likely to survive longer after tracheostomy (Fig. 2). The median survival was 57.5 months ( $\mathrm{IQR}=46-70)$ in patients younger than 60 , whereas it was 38.5 months (IQR $=30-$ 49 ) in the older group ( $p<0.01, \log$-rank test). The Cox proportional hazards model confirmed that lower age at onset is associated with survival in TMV patients (chi-square, 23.31, DF 1, $\mathrm{p}=0.00$ ).

\section{Discussion}

This work is a clinical and survival analysis of a relatively large cohort of ALS patients submitted to TMV and followed-up over a decade, from 2001 to 2010. All patients were followed-up in a single tertiary ALS Center in Palermo, Italy. Tracheostomy was performed in some $30 \%$ of the whole ALS population, with a slightly higher prevalence in men. Tracheostomy significantly prolonged survival, with the stronger effect on patients younger at onset (i.e., less than 60).

TMV is an opportunity for patients with advanced ALS and respiratory failure that up to the recent past have been seldom offered by

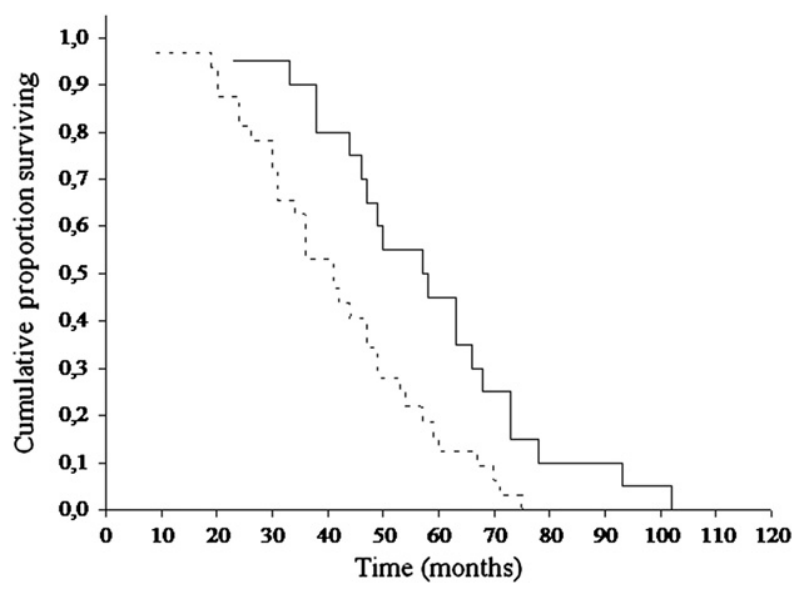

Fig. 2. Kaplan-Meyer survival curve of the TMV ALS patients with age at onset $\leq 60$ years (continuous line; median survival [months] 57.5 [IQR $=46-70]$ ) vs $>60$ years (broken line; median survival [months] $38.5[\mathrm{IQR}=30-49]$ ). $\mathrm{p}=0.002$, log-rank test. neurologists in Europe and North America [27]. TMV may prolong survival in ALS patients and it is now included in the current management guidelines [24,28]. Besides this evidence, tracheostomy rate in ALS patients is still relatively low in most Western countries $[12,17,18,29,30]$, dropping to less than $2 \%$ in two reports $[17,29]$. Conversely, a nationwide study in Japan suggests that at least in that country up to $30 \%$ of ALS patients undergo TMV [11].

We showed that nearly one-third of the ALS patients underwent tracheostomy, a proportion definitively higher than that published in most Western countries. While cultural and religious factors could in part play a role, we suggest that being regularly followed in a tertiary referral ALS Center may be a key variable affecting the relatively high number of tracheostomies observed. Tertiary ALS Centers definitely have a positive impact on the disease management, providing continuous information and education on the disease. A few studies have suggested, in fact, that being followed by ALS Centers increases survival $[5,6]$. Furthermore, improved knowledge about the disease, the dissemination of information through media and TV, and increased resource availability by the Italian Local Health System might also have contributed substantially to the increasing number of tracheostomies.

With regard to sex, in our ALS cohort men were more likely than women to undergo tracheostomy $(\mathrm{M} / \mathrm{F}=1.69)$. A similar ratio (i.e., $\mathrm{M} / \mathrm{F}=1.73$ ) has been reported in a recent population-based study [12]. Other studies show a higher male-to-female proportion among TMV patients, peaking to 2.55 in a Scandinavian survey $[15,31]$. The male prevalence in TMV ALS was instead not confirmed in a Spanish study, where the M/F ratio was 0.72 [10]. The interpretation is that invasive mechanical ventilation is generally underutilized by women. Men may be favored because they have a higher income and/or longer education. In addition, we have preliminary data suggesting a proneness to caregiving in female spouses, which might further favor the use of complex palliative care procedures in men (Spataro $\mathrm{R}$, in preparation). The higher education we found in TMV ALS patients (TMV, median 8 years [IQR $=5-13$ ] vs NT, median 5 years [ $\mathrm{IQR}=5-8], \mathrm{p}=0.008$ ) is an indication that also this variable may actually play a role in the propensity to undergo to tracheostomy. An indirect support to this hypothesis comes from another study which showed that education in TMV ALS patients was higher than controls [13].

Disease progression in ALS is highly variable, from a slow course, over years, to a very rapid evolution from onset to death/tracheostomy. We found that, according to AARS and ALSFRS-R, tracheostomy was more likely to be performed in patients with an intermediate and rapid clinical progression. This is in line with the results of a multivariate analysis which showed that the rate of FVC declined and disease progression is positively associated with a risk to being tracheostomized. Tracheostomies were instead relatively few in the slowly progressing patients, supporting the notion that in this group the development of a severe respiratory failure is an uncommon event [20].

It is known that tracheostomy significantly prolongs survival in ALS bringing patients well beyond the natural history of the disease $[10,12,13]$. If compared with the patients who died without being tracheostomized, we found that those placed into an invasive mechanical ventilation survived a median time of 12 months longer. However, less than $4 \%$ of our TMV ALS patients showed a survival longer than 4 years, and none was alive beyond 5 years. This is in line with another study where it was shown that, among patients undergoing tracheostomy, those with ALS had the poorest long term survival, with only $5 \%$ alive at 5 years [16].

Thirteen out of the fifty-two deceased TMV ALS patients died within the first month after tracheostomy. We found that a relatively low FVC, either as air volumes measured or percent predicted, was associated to this very short survival. It is therefore suggested that a possible optimal timing for tracheostomy, which might allow longer survival, is when FVC is some $32 \%$ predicted and/or when the 
measured air volume is at least 1.31 (Table 3). Although other variables might be implicated in the very short survival of this group of TMV ALS patients, the very low FVC values seem to be an indicator of a poor clinical status, thus making patients highly vulnerable.

Age is another variable who affected survival in our TMV ALS population. We showed that the median survival in TMV ALS patients younger than 60 years was much longer than that of the over 60 group (12 months vs 3.5 months, respectively, $\mathrm{p}=0.024$ ). Tracheostomy does not seem to confer a significant survival advantage in patients older than 60. It is known that being younger at disease onset is associated with a longer natural history of the disease, and this may in part reflect the longer survival after tracheostomy in the under 60 group. If provided with advanced communicative instruments and adequate devices and care to allow independence and well-being, tracheostomy may become a good option in young patients.

In conclusion, by analyzing a cohort of ALS patients followed over a ten-year period in a single ALS Center, we show that tracheostomy is increasingly performed. Nearly all TMV ALS patients live under home care. Survival of ALS patients after tracheostomy is prolonged, particularly in those younger than 60 , and this probably will allow more patients to proceed through this advanced palliative care in the coming years. However, patients should be given full option to decide, by signing advance directives, if and when to interrupt TMV should they wish so. Unfortunately, in several countries, included Italy, the lack of advance directives represents a limit in making an appropriate choice.

\section{Conflict of interest}

Dr Rossella Spataro, Dr Valeria Bono, Dr Santino Marchese, Dr Vincenzo La Bella report no disclosures.

\section{Acknowledgments}

This work was supported by a research grant of the Italian Ministry of Health (no. G71J07000010001). We thank Mr Martin Russell for the careful revision of the English language.

\section{References}

[1] Kiernan MC, Vucic S, Cheah BC, Turner MR, Eisen A, Hardiman O, et al. Amyotrophic lateral sclerosis. Lancet 2011;377:942-55.

[2] Bourke SC, Tomlinson M, Williams TL, Bullock RE, Shaw PJ, Gibson GJ. Effects of non-invasive ventilation on survival and quality of life in patients with amyotrophic lateral sclerosis: a randomised controlled trial. Lancet Neurol 2006;5:140-7.

[3] Spataro R, Ficano L, Piccoli F, La Bella V. Percutaneous endoscopic gastrostomy in amyotrophic lateral sclerosis: effect on survival. J Neurol Sci 2011;304:44-8.

[4] Miller RG, Jackson CE, Kasarskis EJ, England JD, Forshew D, Johnston W, et al Practice parameter update: the care of the patient with amyotrophic lateral sclerosis: multidisciplinary care, symptom management, and cognitive/behavioral impairment (an evidence-based review). Neurology 2009;73:1227-33.

[5] Chiò A, Bottacchi E, Buffa C, Mutani R, Mora G, PARALS. Positive effects of tertiary centres for amyotrophic lateral sclerosis on outcome and use of hospital facilities. J Neurol Neurosurg Psychiatry 2006;77:948-50.

[6] Traynor BJ, Alexander M, Corr B, Frost E, Hardiman O. Effect of a multidisciplinary amyotrophic lateral sclerosis (ALS) clinic on ALS survival: a population-based study, 1996-2000. J Neurol Neurosurg Psychiatry 2003;74:1258-61.

[7] Logroscino G, Traynor BJ, Hardiman O, Chio' A, Couratier P, Mitchell JD, et al. Descriptive epidemiology of amyotrophic lateral sclerosis: new evidence and unsolved issues. J Neurol Neurosurg Psychiatry 2008;79:6-11.
[8] Spataro R, Lo Re M, Piccoli T, Piccoli F, La Bella V. Causes and place of death in Italian patients with amyotrophic lateral sclerosis. Acta Neurol Scand 2010;122: 217-23.

[9] Andersen PM, Borasio GD, Dengler R, Hardiman O, Kollewe K, Leigh PN, et al. EFNS task force on management of amyotrophic lateral sclerosis: guidelines for diagnosing and clinical care of patients and relatives. An evidence-based review with good practice points. Eur J Neurol 2005;12:921-38.

[10] Sancho J, Servera E, Diaz JL, Banũls P, Marin J. Home tracheotomy mechanical ventilation in patients with amyotrophic lateral sclerosis: causes, complications and 1-year survival. Thorax 2011;66:948-52.

[11] Atsuta N, Watanabe H, Ito M, Tanaka F, Tamakoshi A, Nakano I, et al. Age at onset influences on wide-range clinical features of sporadic amyotrophic lateral sclerosis. J Neurol Sci 2009;276:163-9.

[12] Chiò A, Calvo A, Ghiglione P, Mazzini L, Mutani R, Mora G, PARALS. Tracheostomy in amyotrophic lateral sclerosis: a 10-year population-based study in Italy. J Neurol Neurosurg Psychiatry 2010;81:1141-3.

[13] Vianello A, Arcaro G, Palmieri A, Ermani M, Braccioni F, Gallan F, et al. Survival and quality of life after tracheostomy for acute respiratory failure in patients with amyotrophic lateral sclerosis. J Crit Care 2011;26:329.e7-329.e14.

[14] Lo Coco D, Marchese S, La Bella V, Piccoli T, Lo Coco A. The amyotrophic lateral sclerosis functional rating scale predicts survival time in amyotrophic lateral sclerosis patients on invasive mechanical ventilation. Chest 2007;132:64-9.

[15] Moss AH, Oppenheimer EA, Casey P, Cazzolli PA, Roos RP, Stocking CB, et al Patients with amyotrophic lateral sclerosis receiving long-term mechanical ventilation. Advance care planning and outcomes. Chest 1996;110:249-55.

[16] Laub M, Midgren B. Survival of patients on home mechanical ventilation: a nationwide prospective study. Respir Med 2007;101:1074-8.

[17] O'Toole O, Traynor BJ, Brennan P, Sheehan C, Frost E, Corr B, et al. Epidemiology and clinical features of amyotrophic lateral sclerosis in Ireland between 1995 and 2004. J Neurol Neurosurg Psychiatry 2007;79:30-2.

[18] Sorenson EJ, Windbank AJ, Mandrekar JN, Bamlet WR, Appel SH, Armon C, et al. Subcutaneous IGF-1 is not beneficial in 2-year ALS trial. Neurology 2008;71: 1770-5.

[19] Appel V, Stewart SS, Smith G, Appel SH. A rating scale for amyotrophic lateral sclerosis: description and preliminary experience. Ann Neurol 1987;22:328-33.

[20] Cedarbaum JM, Stambler N, Malta E, Fuller C, Hilt D, Thurmond B, et al. The ALSFRS-R: a revised ALS functional rating scale that incorporates assessments of respiratory function. J Neurol Sci 1999;169:13-21.

[21] Brooks BR, Miller RG, Swash M, Munsat TL. El Escorial revisited: revised criteria for the diagnosis of amyotrophic lateral sclerosis. Amyotroph Lateral Scler 2000;1:293-9.

[22] Mannino M, Cellura E, Grimaldi G, Volanti P, Piccoli F, La Bella V. Telephone follow-up for patients with amyotrophic lateral sclerosis. Eur J Neurol 2007;14: 79-84.

[23] Volanti P, Cibella F, Sarvà M, De Cicco D, Spanevello A, Mora G, et al. Predictors of non-invasive ventilation tolerance in amyotrophic lateral sclerosis. J Neurol Sci 2011;303:114-8.

[24] Andersen PM, Borasio GD, Dengler R, Hardiman O, Kollewe K, Leigh PN, et al, EALSC Working Group. Good practice in the management of amyotrophic lateral sclerosis: clinical guidelines. An evidence-based review with good practice points. EALSC Working Group. Amyotroph Lateral Scler 2007;8:195-213.

[25] Kimura F, Fujimura C, Ishida S, Nakajima H, Furutama F, Uehara H, et al. Progression rate of ALSFRS-R at the time of diagnosis predicts survival time in ALS. Neurology 2006;66:265-7

[26] Voustianiouk A, Seidel G, Panchal J, Sivak M, Czaplinski A, Yen A, et al. ALSFRS and Appel ALS scores: discordance with disease progression. Muscle Nerve 2008;37: 668-72.

[27] Borasio GD, Gelinas DF, Yanagisawa N. Mechanical ventilation in amyotrophic lateral sclerosis: a cross-cultural perspective. J Neurol 1998;245(Suppl. 2):S7-S12.

[28] Miller RG, Jackson CE, Kasarskis EJ, England JD, Forshew D, Johnston W, et al. Quality standards subcommittee of the American Academy of Neurology. Practice parameter update: the care of the patient with amyotrophic lateral sclerosis: drug, nutritional and respiratory therapies (an evidence-based review). Neurology 2009;73: tional and 26 .

[29] Ritsma BR, Berger MJ, Charland DA, Khoury MA, Phillips JT, Quon MJ, et al. NIPPV: prevalence, approach and barriers to use at Canadian ALS centres. Can J Neurol Sci 2010;37:54-60.

[30] Zoccolella S, Beghi E, Palagano G, Fraddosio A, Guerra V, Samarelli V, et al. Analysis of survival and prognostic factors in amyotrophic lateral sclerosis: a population-based study. J Neurol Neurosurg Psychiatry 2008;79:30-2.

[31] Tollefsen E, Midgren B, Bakke P, Fondenes O. Amyotrophic lateral sclerosis: gender differences in the use of mechanical ventilation. Eur J Neurol 2010;17:1352-7. 